\title{
Dietary Therapy for Celiac Disease: Suggestions for the Practical Application of the Diet Offered by Gastronomy
}

Judit Molnár ${ }^{1}$ and Mahendra Pal ${ }^{2 *}$

${ }^{1}$ Széchenyi István University, Faculty of Agricultural and Food Sciences, Department of Water and Environmental Sciences, 9200 Mosonmagyaróvár, Hungary.

${ }^{2}$ Narayan Consultancy on Veterinary Public Health and Microbiology- Anand, Gujarat, India.

*Corresponding author: Mahendra Pal, Founder Director of Narayan Consultancy on Veterinary Public Health and Microbiology- Anand, Gujarat, India.

Received date: August 07, 2021; Accepted date: September 11, 2021; Published date: September 20, 2021

Citation: Molnár J., and Mahendra Pal. (2021). Dietary Therapy for Celiac Disease: Suggestions for the Practical Application of the Diet Offered by Gastronomy. J. Nutrition and Food Processing, 4(7); DOI:10.31579/2637-8914/066

Copyright: (c) 2021, Mahendra Pal. This is an open access article distributed under the Creative Commons Attribution License, which permits unrestricted use, distribution, and reproduction in any medium, provided the original work is properly cited.

\begin{abstract}
Celiac disease is an inherited disease. In this case, the protein found in the wheat, barley, rye, and oats $(\alpha-$ gliadin - the alcohol-soluble component of gluten) damages the small intestinal mucosa of the body. As a result of the damage, absorption is impaired. The only way to treat it is through diet, so it is imperative to completely avoid the gluten-containing products. These must be replaced by gluten-free products. The primary purpose of the manuscript is to formulate dietary recommendations for patients with celiac disease. In addition, dishes are prepared and presented that can be an active part of the diet (fried chicken with potato garnish; fruit smoothie with coconut drink; chicken with mixed vegetable salad; fried eggs with fried vegetables and extruded glutenfree cornbread). These foods can be used effectively as part of a gluten-free diet. We hope to provide useful information for the scientific community. In addition, we can contribute to the protection of their health.

Keywords: Celiac disease; $\alpha$-gliadin; Gastronomy; Gluten-free diet; Gluten-free products; Healthy eating; Health preservation
\end{abstract}

\section{Introduction}

Wheat is recognized as the world's most popular cereal and its products can be consumed in a wide variety by the people of all religions [1]. Celiac disease is an inherited disease in which the $\alpha$-gliadin in wheat, barley, rye, and oats damages the small intestinal mucosa of the body. This can cause serious complications. It is mentioned that the $\alpha$-gliadin is an alcoholsoluble component of gluten. In addition to hereditary factors, the environmental factors also play a role in the development of celiac disease [2]. Classical symptoms, such as diarrhoea, abdominal complaints, developmental disorders, loss of appetite and psychiatric signs may help in diagnosing the disease. The diagnosis of celiac disease is the responsibility of gastroenterological centres. The gluten free diet is a way of treating the symptoms of celiac disease [3].The essence of the celiac diet is to exclude the wheat, barley, rye, and oats; and also the foods made from these ingredients from the diet [4]. To replace gluten containing foods, gluten-free specialty products are also available to consumers for their use [5]. The primary purpose of our manuscript is to provide suggestions for a gluten free diet. Furthermore, with the possibilities offered by gastronomy, we prepare and present dishes. These foods can be a useful part of a gluten free diet to treat celiac disease. We hope that with our manuscript, we can contribute to the development of the health and well-being of the scientific community.

\section{Foods that can be used in a gluten-free diet}

Gluten free meals and bakery products: The flour from the cereals (wheat, barley, rye, and oats) that are prohibited in the diet can be replaced by a number of other raw flours or starches. People can use other products, such as rice, potatoes, corn, soybeans, yellow peas and their flours in the diet. In addition, a number of ready-to-eat baked goods, pasta, and cake powder are available to the consumers that are gluten-free. The labelling of gluten free products has been uniformed (crossed-out wheat) and the term "gluten free" has also been used [6].

Fruits and vegetables: The fruits and vegetables work well in the diet as they do not contain gluten. Their vitamin and mineral contents are outstanding and the fiber they contain is also useful for the intestinal function. Semi-finished foods containing fruits and vegetables are not always gluten free $[7,8]$.

Milk and dairy products: Most of the basic milk and dairy products can be used well in the diet. For other dairy products, gluten free labelling is required for the consumers [9]. 
Meats, fish, eggs: Meats, fish [10] and eggs are gluten-free foods. Meat products may contain gluten. Therefore, gluten free markings should be considered when selecting a product. The fats and oils also do not contain gluten, but their consumption needs to be limited according to the requirements of a healthy diet.

Before consuming spices, condiments, drinks, and other supplements, one make sure that these are gluten free. The successful therapy for celiac disease can only be achieved with a gluten free diet. However, the development potential of gluten-free products is becoming increasingly important [11].

\section{The possibilities offered by gastronomy in implementing a gluten-free diet}

In the next part of our manuscript, we prepare and present meals for the practical implementation of a gluten free diet (Figure 1-4). The composition of various food substances and nutritional values of each recipe/cuisine prepared by us is summarized below in each figure. These foods can be a useful part of daily gluten free diet. Only gluten free product was used in the preparation of each dish and potatoes or corn were used to replace the gluten containing ingredients.



Ingredients: Chicken $80 \mathrm{~g}$, oliveoil $5 \mathrm{~g}$, potato $80 \mathrm{~g}$, vegetables $100 \mathrm{~g}$; Energy: 252.6 Kcal, Protein: $19.7 \mathrm{~g}$, Fat: $10 \mathrm{~g}$, Carbohydrate: $19 \mathrm{~g}$

Figure 1: Fried chicken with potato garnish (Own cuisine)

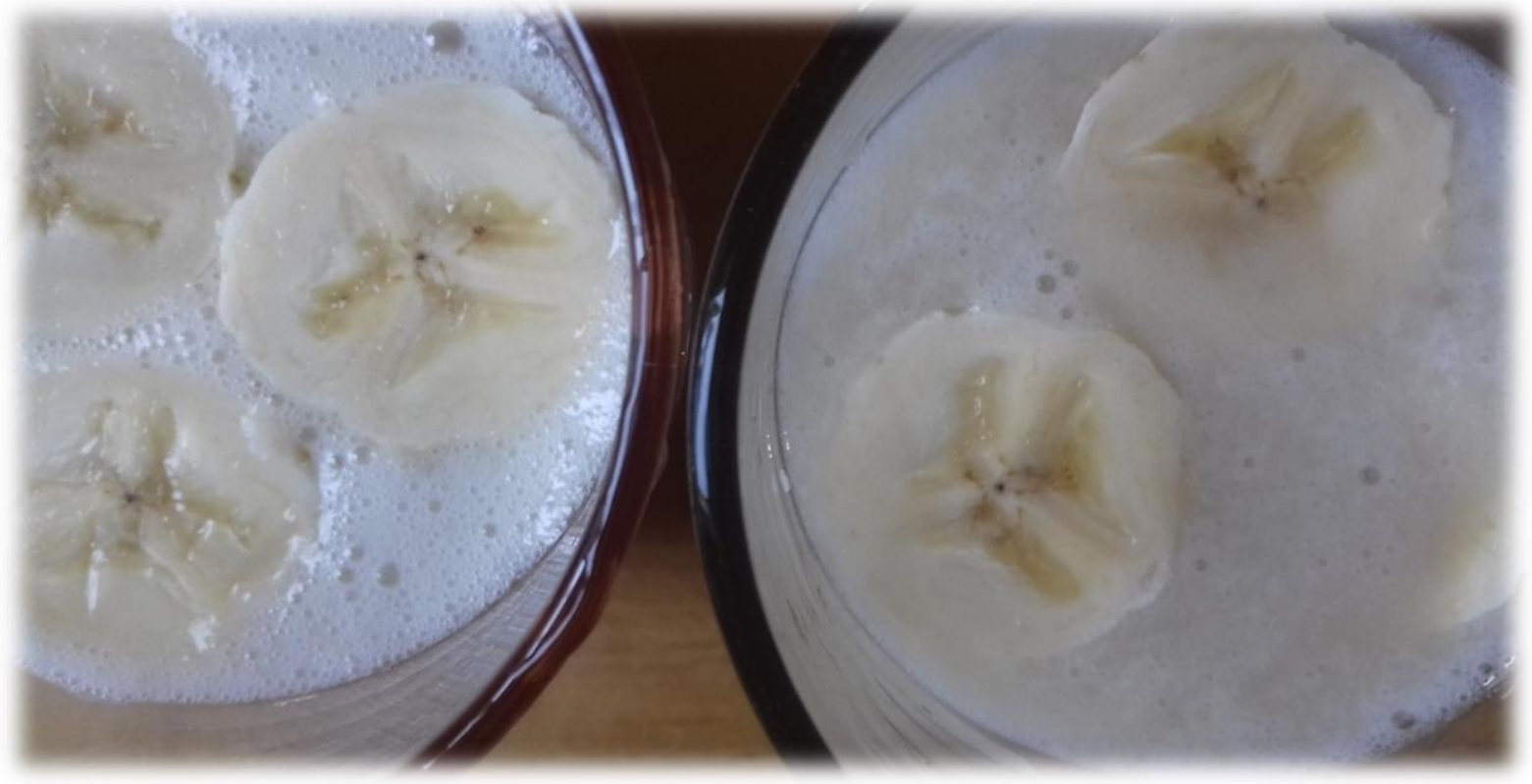

Ingredients: Banana 100 g, gluten free plant based drink 2 dl; Energy: $163 \mathrm{Kcal}$; Protein: $1.7 \mathrm{~g}$; Fat: 1.7 g; Carbohydrate: $27.4 \mathrm{~g}$

Figure 2: Fruits moothie with coconut drink (Own cusine) 


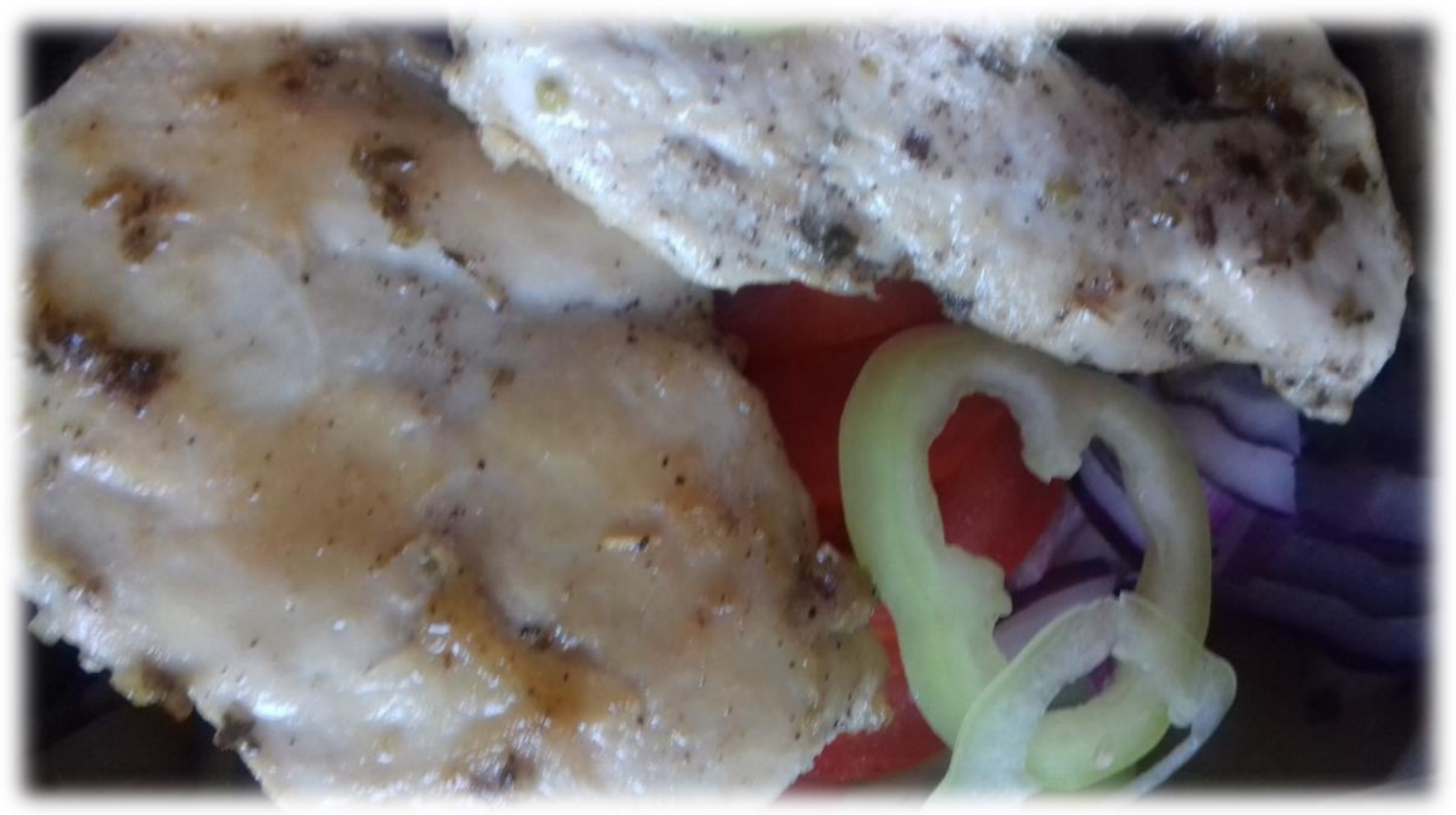

Ingredients: Chicken 80 g; vegetable salad 250 g; Energy: 147 Kcal; Protein: 22.2 g; Fat: 1.3 g; Carbohydrate: 10.4 g

Figure 3: Chicken with mixed vegetable salad (Own cuisine)

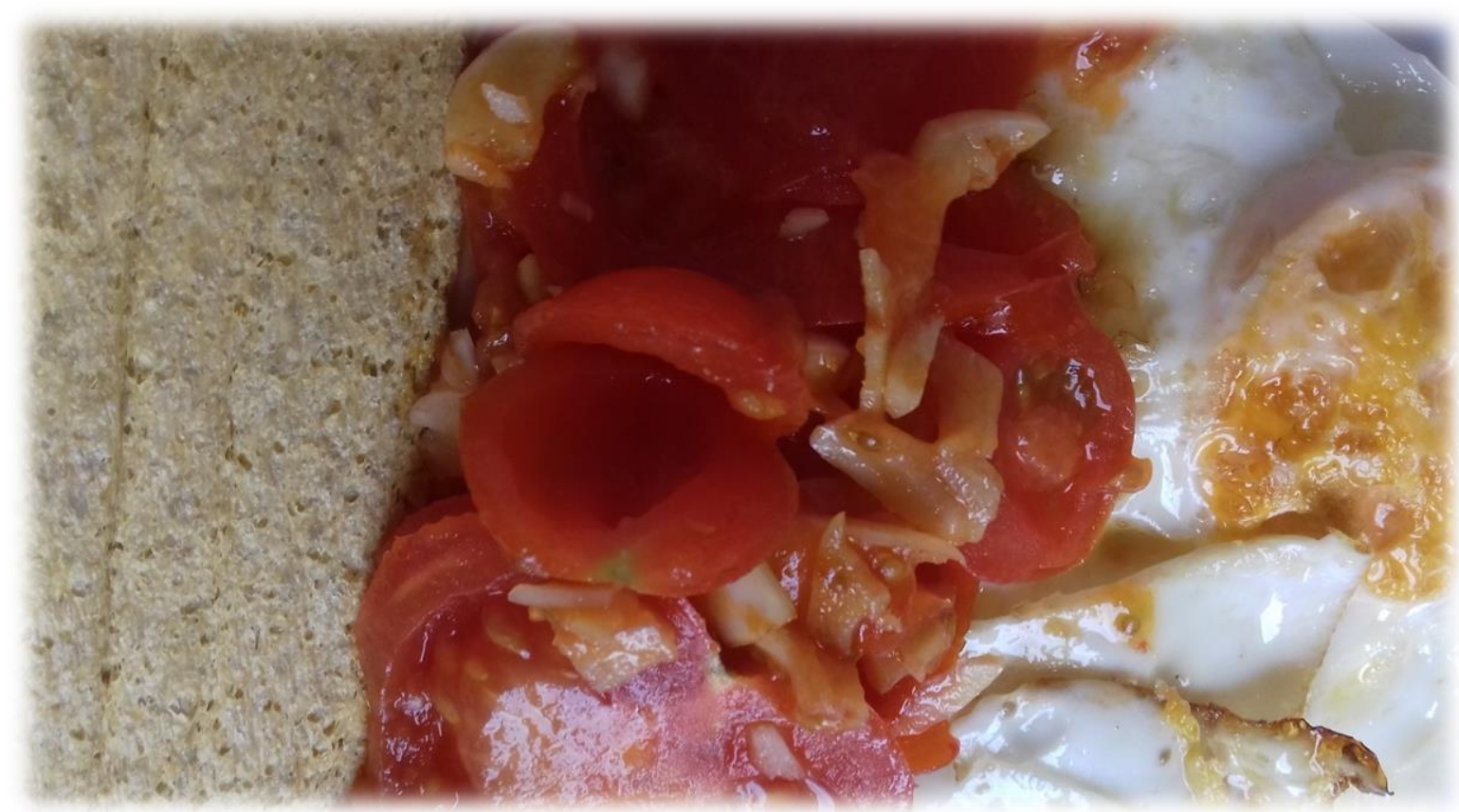

Ingredients: Olive oil 5 g, eggs 2 pieces, vegetables 200 g, gluten free extruded cornbread 2 pieces; Energy: 280 Kcal; Protein: 16.4 g; Fat: 15.3 g; Carbohydrate: $15.5 \mathrm{~g}$

Figure 4: Fried eggs with fried vegetables and extruded gluten-free cornbread (Own cuisine)

\section{Conclusion}

Celiac disease is an inherited disease that can be treated with a gluten-free diet. The essence of the diet is that barley, wheat, oats, and rye and the products made from them should be excluded from the daily diet.These products can be replaced with other items like corn, rice, yellow peas, potatoes, and soy.
By following a complete diet, the symptoms and complications of celiac disease can also be prevented. In our manuscript, we first presented the characteristics of a gluten-free diet, and then we prepared and presented food that can be used in practice. These foods can be supplements to our daily gluten-free diet. By presenting the food, we prepared a gap-filling study. We also considered it important to highlight the labeling requirements for gluten-free products in the present study. These products 
are guaranteed to be safe for diet followers. It is hoped that with our manuscript, we can contribute to the protection of the health of the scientific society and thus to its well-being.

\section{Acknowledgements}

We are very thankful to Prof. Dr. R.K. Narayan for his suggestions during the preparation of manuscript and Anubha Priyabandhu for computer help.This paper is dedicated to Shri Prithviraj Chauhan who is widely known as a warrior king of Delhi. He bravely resisted the Muslim ruler, Muhammad of Ghor, against Islamic invasions by defeating him 16 times. King Prithviraj Chauhan was a great patriotic and loyal to the mother India.

\section{Contribution of authors}

Both the authors contributed equally. They read the final version, and approved it for the publication.

\section{Conflict of interest}

The authors declare that they do not have conflict of interest.

\section{Source of financial grant}

There was no financial support for this manuscript.

\section{References}

1. Ming-yang M, Yang L, Yao-wen Z, Wei-long Q, Zhi-min W, Ying-hua Z, Cong-ming L, Qing-tao L (2021): In situ measurements of winter wheat diurnal changes in photosynthesis and environmental factors reveal new insight into photosynthesis improvement by super-high-yield cultivation. Journal of Integrative Agriculture. 20:527-539.

2. Macho V M P, Manso M C A B M, Silva D M V, Andrade D J C (2020): The difference in symmetry of the enamel defects in celiac disease versus non-celiac paediatric population. Journal of Dental Sciences.15:345-350.
3. Yu X, Vargas J, Green P H R, Bhagat G (2021): Innate lymphoid cells and celiac disease: Current perspective. Cellular and Molecular Gastroenterology and Hepatology.11:803-814.

4. Dotsenko V, Oittinen M, Taavela J, Popp A, Peraaho M, Staff S, Sarin J, Leon F, Isola J, Maki M, Viiri K (2021): Genome wide transcriptomic analysis of intestinal mucosa in celiac disease patients on a gluten-Free diet and postgluten challenge. Cellular and Molecular Gastroenterology and Hepatology.11:13-32.

5. Zafeiropoulou K, Nichols B, Mackinder M, Biskou O, Rizou E, Karanikolou A, Clark C, Buchanan E, Cardigan T, Duncan H, Wands D, Russell J, Hansen R, Russell R K, McGrogan P, Edwards C A, Ijaz U Z, Gerasimidis K (2020): Alterations in intestinal microbiota of children with celiac disease at the time of diagnosis and on a gluten-free diet. Gastroenterology.159:20392051.

6. Wesley S D, André B H M, Clerici M T P S (2021): Gluten free rice and bean biscuit: Characterization of a new food product. Heliyon.7:1-14.

7. Leon J, Pérez-Sáez M J, Uffing A, Murakami N, Watanabe A, Cureton P, Kenyon V, Keating L, Yee K, Satiro C A F, Yu B, Bonventre J V, Fasano A, Riella L V (2018): Effect of combined gluten-free, dairy-free diet in children with steroid-resistant nephrotic syndrome: An open pilot trial. Kidney International Reports.3:851-860.

8. Bolarinwa I F, Oyesiji O O (2021): Gluten free rice-soy pasta: proximate composition, textural properties and sensory attributes. Heliyon.7:1-7.

9. Ferreira S M, Caliari M, Júnior M S S, Beleia A D P (2014): Infant dairy-cereal mixture for the preparation of a gluten free cream using enzymatically modified rice flour. Food Science and Technology.59:1033-1040.

10. Wünsche J, Lambert C, Gola U, Biesalski H K (2018): Consumption of gluten free products increases heavy metal intake. Nutrition and Food Science Journal.12:11-15.

11. Jnawali P, Kumar V, Tanwar B (2016): Celiac disease: Overview and considerations for development of gluten-free foods. Food Science and Human Wellness.5:169-176.

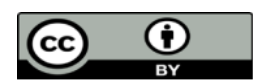

This work is licensed under Creative Commons Attribution 4.0 License
Ready to submit your research? Choose Auctores and benefit from:

$>$ fast, convenient online submission

$>$ rigorous peer review by experienced research in your field

$>$ rapid publication on acceptance

$>$ authors retain copyrights

$>$ unique DOI for all articles

$>$ immediate, unrestricted online access

At Auctores, research is always in progress.

Learn more https://auctoresonline.org/journals/nutrition-and-foodprocessing 